\title{
Internal Rotation of Disilane and Related Molecules: a Density Functional Study ${ }^{1}$
}

\author{
Felipe Valencia ${ }^{a}$ Aldo H. Romero ${ }^{a}$ Miguel Kiwi ${ }^{a}$ \\ Ricardo Ramírez ${ }^{a}$ Alejandro Toro-Labbéb ${ }^{b}$ \\ ${ }^{a}$ Facultad de Física, Universidad Católica de Chile \\ Casilla 306, Santiago, CHILE 6904411 \\ ${ }^{\mathrm{b}}$ Facultad de Química, Universidad Católica de Chile \\ Casilla 306, Santiago, CHILE 6904411
}

\begin{abstract}
DFT calculations performed on $\mathrm{Si}_{2} \mathrm{H}_{6}, \mathrm{Si}_{2} \mathrm{~F}_{6}, \mathrm{Si}_{2} \mathrm{Cl}_{6}$, and $\mathrm{Si}_{2} \mathrm{Br}_{6}$ are reported. The evolution of the energy, the chemical potential and the molecular hardness, as a function of torsion angle, is studied. Results at the DFT-B3LYP/6-311++G** level show that the molecules always favor the stable staggered conformations, with low but significant energy barriers that hinder internal rotation. The chemical potential and hardness of $\mathrm{Si}_{2} \mathrm{H}_{6}$ remains quite constant as the sylil groups rotate around the $\mathrm{Si}-\mathrm{Si}$ axis, whereas the other systems exhibit different degrees of rearrangement of the electronic density as a function of the torsion angle. A qualitative analysis of the frontier orbitals shows that the effect of torsional motion on electrophilic attack is negligible, whereas this internal rotation may generate different specific mechanisms for nucleophilic attack.
\end{abstract}

Key words: internal rotation, Ab initio calculations, potential energy surfaces, conformations, electron affinities

PACS: 31.10.+z: Theory of electronic structure, electronic transitions, and chemical binding, 31.15.Ar: Ab initio calculations, 31.50.Bc: Potential energy surfaces for ground electronic states, 33.15.-e: Properties of molecules

Email addresses: fvalencia@bethe.fis.puc.cl (Felipe Valencia), ahromero@puc.cl (Aldo H. Romero), mkiwi@puc.cl (Miguel Kiwi), rramirez@puc.cl (Ricardo Ramírez), atola@puc.cl (Alejandro Toro-Labbé).

1 Supported by the Fondo Nacional de Desarrollo Científico y Tecnológico (FONDECYT, Chile) under grants \#8990005, 1020534 and 1010988. 


\section{Introduction}

Recently disilane has attracted attention (1; 2) due to its importance in the production of silicon based semiconductor devices. Its geometry is quite similar to ethane, which is the best known and most widely studied example (3; $4 ;$; 5 ; 6) of simple molecules with properties that markedly depend on the rotation of a group of atoms around one or more internal bonds, going through stable and unstable conformations as a full $360^{\circ}$ rotation is executed. In particular, the central $\mathrm{C}-\mathrm{C}$ bond of ethane is a threefold symmetry axis. Thus, as one of the two methyl groups rotates around this axis the molecule goes through (stable) staggered and (unstable) eclipsed conformations (see Fig. 1). The preferred staggered structure is attributed to steric effects (3; 4; 5; 6; 7; 8), more precisely to increased repulsion between electrons in bonds that are drawn closer together (6).

On the other hand, the fundamental processes in the disilane decomposition on silicon surfaces are relevant to the understanding and optimization of the growth of epitaxial silicon on silicon substrates. The morphological parameters of the eclipsed and staggered silane conformations were recently calculated by Pophristic and co-workers (目). They concluded that the origin of the eclipsed to staggered relaxation is related to the preferential hyperconjugative stabilization (meaning energy stabilization through electron excitation to a delocalized state). This charge delocalization changes the electronic properties of the molecule, as a function of the conformation it adopts.

When a reaction moves forward along the reaction coordinate, a redistribution of the ground-state electron density takes place, and the resulting energy change can be understood in terms of the response of the system to variations of the total number of electrons $N$, and of the external $v(\vec{r})$ potential (11). Density functional theory (DFT) (11; 12) has been quite successful in providing a theoretical basis for qualitative chemical concepts like chemical potential $(\mu)$ and hardness $(\eta)$, which describe the response of the system when $N$ is varied for a fixed $v(\vec{r})$ (11). In DFT $\mu$ is the Lagrange multiplier associated with the normalization constraint that requires conservation of the number of electrons $N$. Classical structural chemistry is recovered with the identification of $\mu$ as minus the electronegativity $(\mu=-\chi)$, a well known and well established quantity. Definitions of $\mu$ and $\eta$, two global electronic properties that are implied in the reactivity of molecular systems, were given by Parr et al. (13) and Parr and Pearson (14; 15), respectively. The application of DFT concepts to the analysis of chemical reactions is better appreciated with the help of the principle of maximum hardness $(\mathrm{PMH})$, that asserts that molecular systems reach equilibrium tending towards states with the highest hardness (16; 17). In this context the PMH can also be helpful in identifying transition states where minimum values of $\eta$ are expected (18). 
The main purpose of this paper is to provide a detailed report on the geometric and electronic structure of disilane $\left(\mathrm{Si}_{2} \mathrm{H}_{6}\right)$ and the family of closely related molecules $\mathrm{Si}_{2} \mathrm{X}_{6}$, where $\mathrm{X}=\mathrm{F}, \mathrm{Cl}$ and $\mathrm{Br}$, as well as the implications this structure has on the molecular properties. We focus our attention on the changes that are induced on the energy and molecular properties as the molecular conformation periodically changes from staggered to eclipsed and back to staggered through rotation with respect to the $\mathrm{Si}-\mathrm{Si}$ bond of the $\mathrm{SiX}_{3}$ group of $\mathrm{Si}_{2} \mathrm{X}_{6}(\mathrm{X}=\mathrm{H}, \mathrm{F}, \mathrm{Cl}, \mathrm{Br})$.

This paper is organized as follows: after this introduction we discuss technical aspects of our calculation in Sec. 2, discuss the molecular geometry in Sec. 3, the electronic energy profiles and rotational barriers in Sec. 4 and the chemical potential and the hardness in Sec. 5. In Sec. 6 we present a qualitative analysis of the chemical reactivity of silanes and finally, we close the paper in Sec. 7 drawing conclusions.
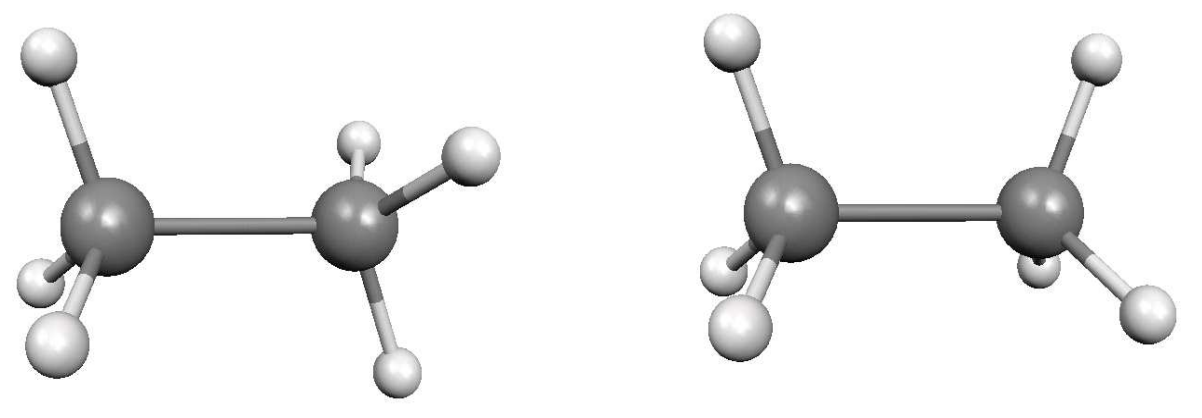

Fig. 1. Staggered (left) and eclipsed (right) conformations. The rotation angle $\alpha=0^{\circ}$ for the staggered and $\alpha=60^{\circ}$ for the eclipsed conformations, respectively.

\section{Computational Details}

The calculations reported in this paper were performed using the Gaussian 98 (9) package. The results we report were obtained implementing the B3LYPDFT method and corresponds to the B3LYP/6-311++G** level. A lower level B3LYP/6-31G* calculation was tested for comparison purposes. For the staggered and eclipsed conformations, and in order to test the DFT results, MP2/6-311++G** calculations were also carried out to check the quality of the B3LYP results. 


\section{Geometry}

Constrained geometrical optimization was performed varying the dihedral angle $\alpha$, defined as the rotation angle of the silyl group of $\mathrm{Si}_{2} \mathrm{H}_{6}$ (or the three $\mathrm{X}$ atoms in $\mathrm{Si}_{2} \mathrm{X}_{6}$ ), located at one end of the $\mathrm{Si}-\mathrm{Si}$ bond, relative to the same three atoms at the other end of this bond (see the illustration in Fig. 1). The angle $0 \leq \alpha<60^{\circ}$, with $\alpha=0$ defined as the staggered conformation and $\alpha=60^{\circ}$ as the eclipsed one, is varied in steps of $10^{\circ}$.

The structural parameters obtained for the staggered conformation are listed and compared to experimental data -whenever the latter is available- in Table 1. It is apparent that for the lighter molecules (i.e. $\mathrm{Si}_{2} \mathrm{H}_{6}$ and $\mathrm{Si}_{2} \mathrm{~F}_{6}$ ) B3LYP /6-31G* yields better agreement with experimental values than B3LYP /6-311++ $\mathrm{G}^{* *}$, while the larger basis set 6-311++G** fares better for $\mathrm{Si}_{2} \mathrm{Cl}_{6}$. We expect the same to hold for $\mathrm{Si}_{2} \mathrm{Br}_{6}$ (a molecule that has not yet been synthesized) since heavier atoms require larger basis sets for a proper description. Thus, in what follows below, our comparisons with experiment are based upon the results of $\mathrm{B} 3 \mathrm{LYP} / 6-311++\mathrm{G}^{* *}$.

Rotation of one sylil group with respect to the staggered conformation is accompanied by a significant change in the Si-Si distance (see Fig. 2) while the $\mathrm{Si}-\mathrm{X}(\mathrm{X}=\mathrm{H}, \mathrm{F}, \mathrm{Cl}$ and $\mathrm{Br}$ ) distance remains almost unchanged (see Table 1). In fact, $\mathrm{Si}_{2} \mathrm{Br}_{6}$ displays the largest deformation, which amounts to about $1.59 \%$, while $\mathrm{Si}_{2} \mathrm{~F}_{6}$ undergoes a tiny elongation of only $0.23 \%$.

The angle $\angle(\mathrm{SiSiX})$, between the $\mathrm{Si}$ axis and the $\mathrm{X}$-atoms, exhibits a small but systematic increase as a function of $\alpha$. Again, this change is largest for $\mathrm{Si}_{2} \mathrm{Br}_{6}$ (approximately $0.66 \%$ ) and smallest for $\mathrm{Si}_{2} \mathrm{~F}_{6}$ (approximately $0.04 \%$ ).

\section{Energy Profiles and Rotational Barriers}

Fig. 3 shows the evolution of the total energy for each molecule studied, measured with respect to the total energy in the staggered configuration. In each case, staggered conformation is of minimum energy and eclipsed conformation presents maximum energy.

It is also evident from Figs. 2 and 3 that the energy follows the same trend as the Si-Si distance along the torsional angle. Clearly, the torsional potential energy can be understood in terms of the structural changes of the molecule undergoes as $\alpha$ is varied. $\mathrm{Si}_{2} \mathrm{~F}_{6}$ being almost free to rotate, in the sense that it undergoes only minor geometrical changes, presents a rather small rotational barrier of $\sim 0.61 \mathrm{kcal} / \mathrm{mol}$, while $\mathrm{Si}_{2} \mathrm{Br}_{6}$ has a rotational barrier of $\sim 2.6$ 


\begin{tabular}{|c|c|c|c|}
\hline Molecule & B3LYP/6-31G* & B3LYP $/ 6-311++\mathrm{G}^{* *}$ & Experiment \\
\hline \multicolumn{4}{|l|}{$\mathrm{Si}_{2} \mathrm{H}_{6}$ (staggered) } \\
\hline $\mathrm{d}(\mathrm{Si}-\mathrm{Si})$ & 2.350 & 2.354 & 2.331 (2) \\
\hline $\mathrm{d}(\mathrm{Si}-\mathrm{H})$ & 1.489 & 1.487 & 1.492 (2) \\
\hline$\angle(\mathrm{SiSiH})$ & 110.4 & 110.6 & 110.3 (2) \\
\hline \multicolumn{4}{|l|}{$\mathrm{Si}_{2} \mathrm{H}_{6}$ (eclipsed) } \\
\hline $\mathrm{d}(\mathrm{Si}-\mathrm{Si})$ & 2.360 & 2.366 & \\
\hline $\mathrm{d}(\mathrm{Si}-\mathrm{H})$ & 1.489 & 1.487 & \\
\hline$\angle(\mathrm{SiSiH})$ & 110.8 & 110.6 & \\
\hline \multicolumn{4}{|l|}{$\mathrm{Si}_{2} \mathrm{~F}_{6}$ (staggered) } \\
\hline $\mathrm{d}(\mathrm{Si}-\mathrm{Si})$ & 2.319 & 2.336 & 2.317 (2) \\
\hline $\mathrm{d}(\mathrm{Si}-\mathrm{F})$ & 1.593 & 1.598 & 1.564 (2) \\
\hline$\angle(\mathrm{SiSiF})$ & 110.5 & 110.7 & 110.3 (2) \\
\hline \multicolumn{4}{|l|}{$\mathrm{Si}_{2} \mathrm{~F}_{6}$ (eclipsed) } \\
\hline $\mathrm{d}(\mathrm{Si}-\mathrm{Si})$ & 2.326 & 2.341 & \\
\hline $\mathrm{d}(\mathrm{Si}-\mathrm{F})$ & 1.592 & 1.598 & \\
\hline$\angle(\mathrm{SiSiF})$ & 110.7 & 110.7 & \\
\hline \multicolumn{4}{|l|}{$\mathrm{Si}_{2} \mathrm{Cl}_{6}$ (staggered) } \\
\hline $\mathrm{d}(\mathrm{Si}-\mathrm{Si})$ & 2.355 & 2.354 & 2.320 \\
\hline $\mathrm{d}(\mathrm{Si}-\mathrm{Cl})$ & 2.060 & 2.056 & 2.002 \\
\hline$\angle(\mathrm{SiSiCl})$ & 109.7 & 109.6 & \\
\hline \multicolumn{4}{|l|}{$\mathrm{Si}_{2} \mathrm{Cl}_{6}$ (eclipsed) } \\
\hline $\mathrm{d}(\mathrm{Si}-\mathrm{Si})$ & 2.377 & 2.378 & \\
\hline $\mathrm{d}(\mathrm{Si}-\mathrm{Cl})$ & 2.059 & 2.056 & \\
\hline$\angle(\mathrm{SiSiCl})$ & 110.0 & 109.9 & \\
\hline \multicolumn{4}{|l|}{$\mathrm{Si}_{2} \mathrm{Br}_{6}$ (staggered) } \\
\hline $\mathrm{d}(\mathrm{Si}-\mathrm{Si})$ & 2.335 & 2.368 & \\
\hline $\mathrm{d}(\mathrm{Si}-\mathrm{Br})$ & 2.211 & 2.232 & \\
\hline$\angle(\mathrm{SiSiBr})$ & 108.7 & 109.2 & \\
\hline \multicolumn{4}{|l|}{$\mathrm{Si}_{2} \mathrm{Br}_{6}$ (eclipsed) } \\
\hline $\mathrm{d}(\mathrm{Si}-\mathrm{Si})$ & 2.356 & 2.405 & \\
\hline $\mathrm{d}(\mathrm{Si}-\mathrm{Br})$ & 2.209 & 2.232 & \\
\hline$\angle(\mathrm{SiSiBr})$ & 108.7 & 110.0 & \\
\hline
\end{tabular}




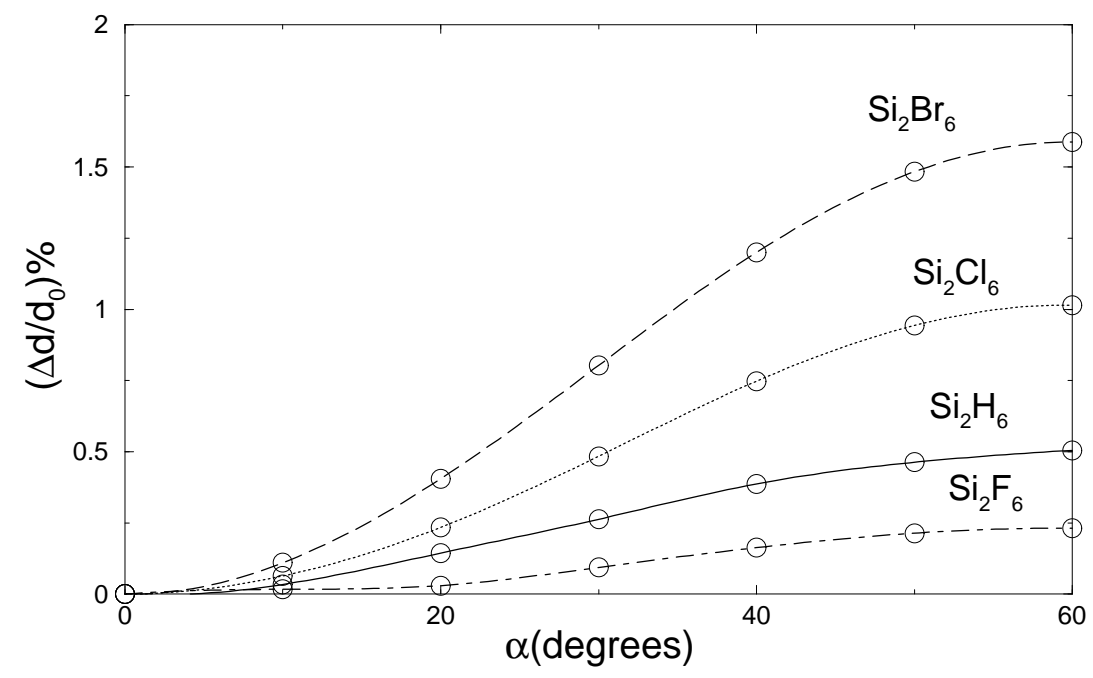

Fig. 2. Change of the Si-Si distance for the four molecules studied, in percentages. The open circles are the calculated points and the lines are guides to the eye.

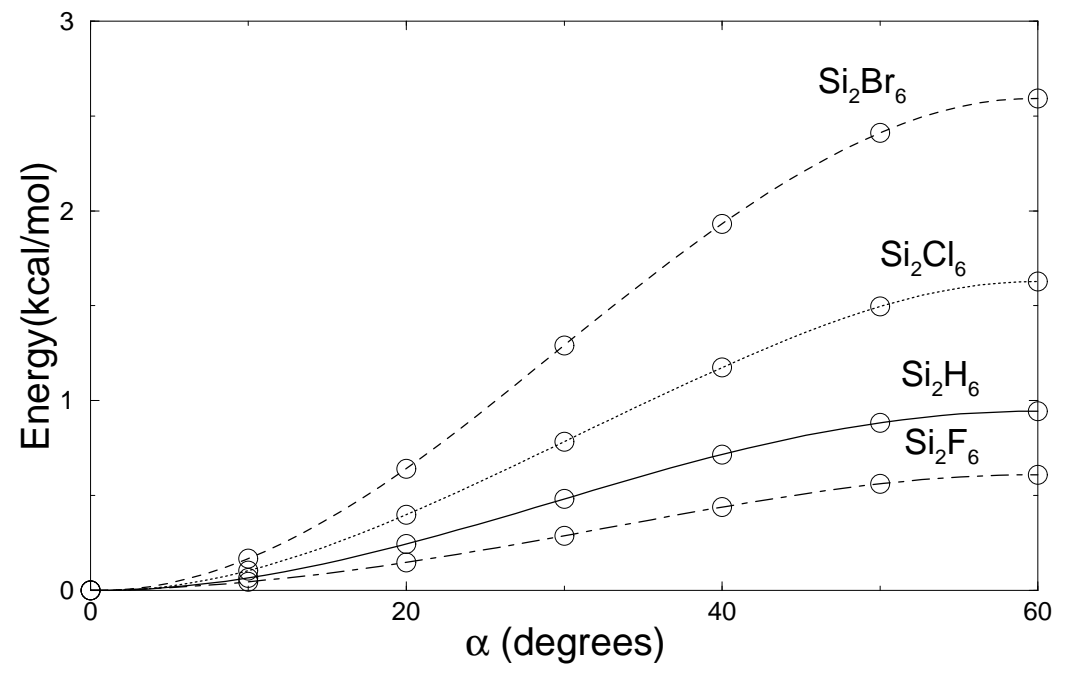

Fig. 3. Electronic energy as function of torsion angle $\alpha$. The open circles are the calculated points and the lines are guides to the eye.

$\mathrm{kcal} / \mathrm{mol}$, consistent with its larger geometric changes. The above results indicate that torsional potential barriers, that hinder the interconversion between two staggered conformations, arise from structural rearrangements induced by an interplay between steric repulsion and hyperconjugation effects (7).

It is important to remark that at the $\mathrm{B} 3 \mathrm{LYP} / 6-31 \mathrm{G}^{*}$ level $\mathrm{Si}_{2} \mathrm{Br}_{6}$ is predicted to be stable in the eclipsed configuration, with a rather significant energy difference of $1.17 \mathrm{kcal} / \mathrm{mol}$ relative to the staggered one. MP2/6-31G* also yields a smaller energy for the eclipsed configuration, but with a much smaller difference of only $0.150 \mathrm{kcal} / \mathrm{mol}$. However, the $\mathrm{MP} 2 / 6-311++\mathrm{G}^{* *}$ calculations agree with the $\mathrm{B} 3 \mathrm{LYP} / 6-311++\mathrm{G}^{* *}$ results. Thus, it seems that $6-311++\mathrm{G}^{* *}$ 
Table 2

\begin{tabular}{|c|c|}
\hline Molecule & Rotational Barrier $(\mathrm{kcal} / \mathrm{mol})$ \\
\hline \hline $\mathrm{Si}_{2} \mathrm{H}_{6}$ & 0.9441 \\
\hline $\mathrm{Si}_{2} \mathrm{~F}_{6}$ & 0.6096 \\
\hline $\mathrm{Si}_{2} \mathrm{Cl}_{6}$ & 1.6272 \\
\hline $\mathrm{Si}_{2} \mathrm{Br}_{6}$ & 2.5920 \\
\hline
\end{tabular}

Calculated rotational barrier at the B3LYP $/ 6-311++\mathrm{G}^{* *}$ level for $\mathrm{Si}_{2} \mathrm{H}_{6}, \mathrm{Si}_{2} \mathrm{~F}_{6}, \mathrm{Si}_{2} \mathrm{Cl}_{6}$ and $\mathrm{Si}_{2} \mathrm{Br}_{6}$

is the minimum basis set required to correctly describe the rotational behavior of $\mathrm{Si}_{2} \mathrm{Br}_{6}$.

Table 2 displays the B3LYP/6-311++ $\mathrm{G}^{* *}$ rotational barriers we obtained. Substitution of the hydrogens, by the more electronegative fluor atoms, results in a lowering of the potential barrier. The electronic population is now mainly localized at the $\mathrm{SiF}_{3}$ groups thus weakening the $\mathrm{Si}-\mathrm{Si}$ torsional bond. The values for $\mathrm{Si}_{2} \mathrm{H}_{6}$ and $\mathrm{Si}_{2} \mathrm{~F}_{6}$ compare well with those calculated by Cho et al. (2). The experimental values for the rotational barrier of $\mathrm{Si}_{2} \mathrm{H}_{6}$ are $\sim 1$ $\mathrm{kcal} / \mathrm{mol}$, and for $\mathrm{Si}_{2} \mathrm{~F}_{6}$ between $0.51-0.73 \mathrm{kcal} / \mathrm{mol}$, according to early electron diffraction measurements (2).

On the other hand, substitution of the hydrogens by chlorine and bromine atoms tends to keep the electronic population uniformly distributed, and the observed increase of the potential barrier seems to be related to steric hindrance between quite voluminous chemical groups.

\section{Chemical Potential and Hardness}

In DFT the chemical potential of a molecule is defined by the derivative of the energy with respect to the number of electrons $N$ at constant external potential $v(r)$ :

$$
\mu=\left(\frac{\partial E}{\partial N}\right)_{v(r)}
$$

where $E$ is the energy and $N$ the number of particles. For a finite system this extrapolation takes the form (11)

$$
\mu \cong \frac{1}{2}[E(N+1)-E(N-1)]
$$


Moreover, following Koopmans' theorem (19), the anion energy $E(N+1)$ can be approximated by $E(N+1) \approx E(N)+E_{\mathrm{LUMO}}$, and the cation energy $E(N-1)$, by $E(N-1) \approx E(N)-E_{\mathrm{HOMO}}$, where $E_{\mathrm{LUMO}}$ and $E_{\mathrm{HOMO}}$ are the energies of the Lowest Unoccupied and Highest Occupied Molecular Orbital, respectively. Within this approximation

$$
\mu \cong \frac{1}{2}\left(E_{\mathrm{LUMO}}+E_{\mathrm{HOMO}}\right)
$$

Another relevant characteristic property we want to probe is the chemical hardness $\eta$, defined as

$$
\eta=\frac{1}{2}\left(\frac{\partial^{2} E}{\partial N^{2}}\right)_{v(r)},
$$

which can be approximated by a finite difference as follows:

$$
\eta \cong \frac{1}{2}[E(N+1)+E(N-1)-2 E(N)]
$$

which in terms of the HOMO-LUMO energies reads

$$
\eta \cong \frac{1}{2}\left[E_{\mathrm{LUMO}}-E_{\mathrm{HOMO}}\right]
$$

Nevertheless it is important to notice that the actual changes in the torsional energy must include the geometrical changes induced by the removal or addition of electrons. This geometrical relaxation may include symmetry changes, such as the rotations around the Si-Si axis we study in this paper. Thus, the significance of $\eta$ and $\mu$ as calculated above, whether with the HOMO-LUMO approximation or with the unrelaxed (or constraint relaxed) cation and anion energies, is not completely accurate.

Figs. 4 and 5 display the chemical potential $\mu$ and chemical hardness $\eta$, respectively, as a function of the torsion angle $\alpha$, in the HOMO-LUMO approximation. An appreciably difference of the $\mu$ values between two reference conformations implies that an electronic rearrangement, with some charge transfer from the higher towards the lower $\mu$ conformation, will take place. By inspection of Fig. 4 we observe that the chemical potential versus $\alpha$ profiles for all molecules, except $\mathrm{Si}_{2} \mathrm{H}_{6}$, display a variation of $\mu \sim 1 \mathrm{kcal} / \mathrm{mol}$ as $\alpha$ varies by $60^{\circ}$, always opposite in sign to the relative to the energy variation displayed in Fig. 5. This is an indication that torsion implies a rearrangement of the electronic density. In contrast, for $\mathrm{Si}_{2} \mathrm{H}_{6}$, the chemical potential remains quite constant over the range $0 \geq \alpha \geq 60^{\circ}$, with $\Delta \mu \sim 0.10 \mathrm{kcal} / \mathrm{mol}$. 


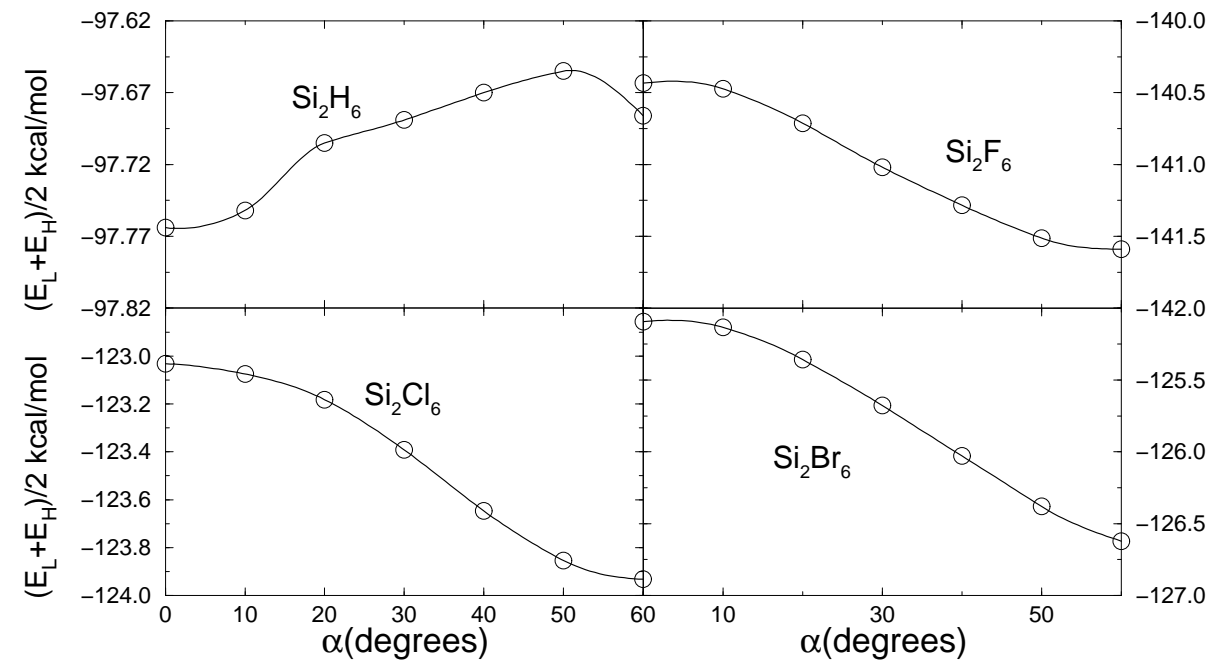

Fig. 4. Chemical potential in the HOMO-LUMO approximation

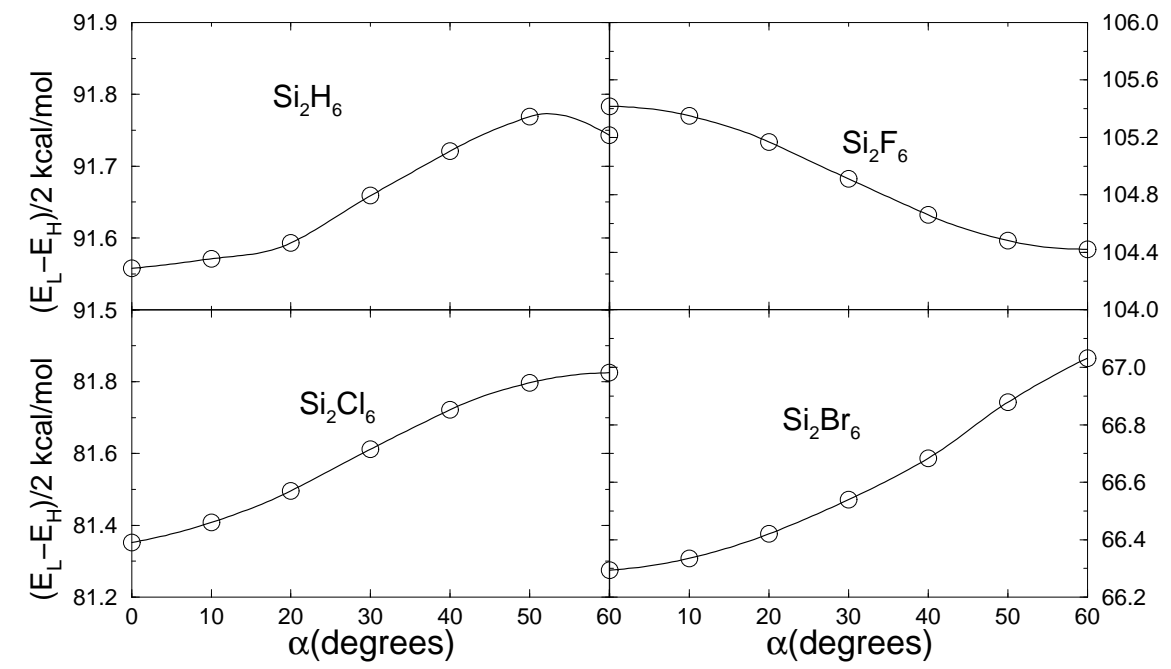

Fig. 5. Chemical hardness in the HOMO-LUMO approximation.

Further inspection of Fig. 5 reveals that the overall hardness changes are quite small, ranging from $\sim 0.2 \mathrm{kcal} / \mathrm{mol}$ for $\mathrm{Si}_{2} \mathrm{H}_{6}$ to $\sim 1 \mathrm{kcal} / \mathrm{mol}$ for $\mathrm{Si}_{2} \mathrm{~F}_{6} \cdot \mathrm{Si}_{2} \mathrm{H}_{6}$, $\mathrm{Si}_{2} \mathrm{Cl}_{6}$ and $\mathrm{Si}_{2} \mathrm{Br}_{6}$ are chemically hardest in the eclipsed conformation, while $\mathrm{Si}_{2} \mathrm{~F}_{6}$ is hardest in the staggered conformation. It is interesting to mention that the same trends for the chemical hardness are predicted both by the cationanion energies, at the B3LYP/6-311++ $\mathrm{G}^{* *}$ level, and by the HOMO-LUMO approximation at MP2/6-311++ $\mathrm{G}^{* *}$ level, as seen in Table 3, where the numerical values of the hardness in the staggered and eclipsed conformations are listed.

It is noticed that the $\mathrm{PMH}$ is verified only for $\mathrm{Si}_{2} \mathrm{~F}_{6}$, while $\mathrm{Si}_{2} \mathrm{H}_{6}, \mathrm{Si}_{2} \mathrm{Cl}_{6}$ and $\mathrm{Si}_{2} \mathrm{Br}_{6}$ present hardness profiles obeying the same trend as their energy profiles. According to the $\mathrm{PMH}$, the hardness profile of $\mathrm{Si}_{2} \mathrm{~F}_{6}$ displays a maximum at the stable staggered conformation and a minimum at the unstable eclipsed 


\begin{tabular}{|c|c|c|c|}
\hline Molecule & HOMO-LUMO, B3LYP & ANION CATION, B3LYP & HOMO-LUMO, MP2 \\
\hline \hline $\mathrm{Si}_{2} \mathrm{H}_{6}$ & 0.185 & 0.308 & 0.52 \\
\hline $\mathrm{Si}_{2} \mathrm{~F}_{6}$ & -0.995 & -0.856 & -0.90 \\
\hline $\mathrm{Si}_{2} \mathrm{Cl}_{6}$ & 0.473 & 0.634 & \\
\hline $\mathrm{Si}_{2} \mathrm{Br}_{6}$ & 0.738 & 1.071 & 1.39 \\
\hline
\end{tabular}

Table 3

Change in chemical hardness $\Delta \eta=\eta_{e}-\eta_{s}$ in $\mathrm{kcal} / \mathrm{mol}$.

conformation. We want to emphasize the complementary behavior of energy and hardness: whereas for $\mathrm{Si}_{2} \mathrm{~F}_{6}$ the almost free internal rotation does not allow to distinguish the energetically most favorable $\alpha$ value, the hardness profile allows this characterization. In contrast, the hindered rotation in $\mathrm{Si}_{2} \mathrm{X}_{6}$ $(\mathrm{X}=\mathrm{H}, \mathrm{Cl}, \mathrm{Br})$ yields energetically distinguishable conformations, but they cannot be characterized by the hardness profiles.

\section{$6 \quad$ Reactivity of Silanes}

The reactivity of these systems, induced by the internal rotation, cannot be rationalized in terms of the profiles of $\mu$ and $\eta$ alone, due to their almost constant behavior as a function of $\alpha$. However, a different perspective of the electronic structure and reactivity is provided by the LUMO and HOMO densities. In Fig. 6 the HOMO of the $\mathrm{Si}_{2} \mathrm{H}_{6}$ molecule is shown and we observe very similar orbitals to the other $\mathrm{Si}_{2} \mathrm{X}_{6}$ molecules we have considered. The majority of the orbital charge accumulates on the $\mathrm{Si}-\mathrm{Si}$ bond with some contribution on the hydrogens, and with a bond of clear $\pi$-character. Moreover, there is little difference between the HOMO staggered and eclipsed charge distributions, indicating that the effect of the torsional motion on an electrophilic attack is negligible.

The LUMO electronic structure, as illustrated in Fig. 7, is completely different. For $\mathrm{Si}_{2} \mathrm{H}_{6}$, in the lowest energy (staggered) configuration, the charge density is delocalized on the sylil groups. Moreover, inspection of Figs. 6 and 7 , shows that the largest overlap between HOMO and LUMO orbitals occurs for $\mathrm{Si}_{2} \mathrm{~F}_{6}$, which suggests that in the staggered configuration this molecule has the strongest hyperconjugative effects (7). On the contrary, in the eclipsed conformation the charge is delocalized on the $\mathrm{Si}$-Si bond, with a $\pi$-antibond character. This indicates that a nucleophilic attack on $\mathrm{Si}_{2} \mathrm{H}_{6}$ may present different specific mechanisms, as a consequence of the low torsion barrier. In the $\mathrm{Si}_{2} \mathrm{~F}_{6}$ staggered configuration the delocalization process is different: the charge is delocalized on the $\mathrm{Si}-\mathrm{Si}$ bond, with antibond character, and is symmetric 

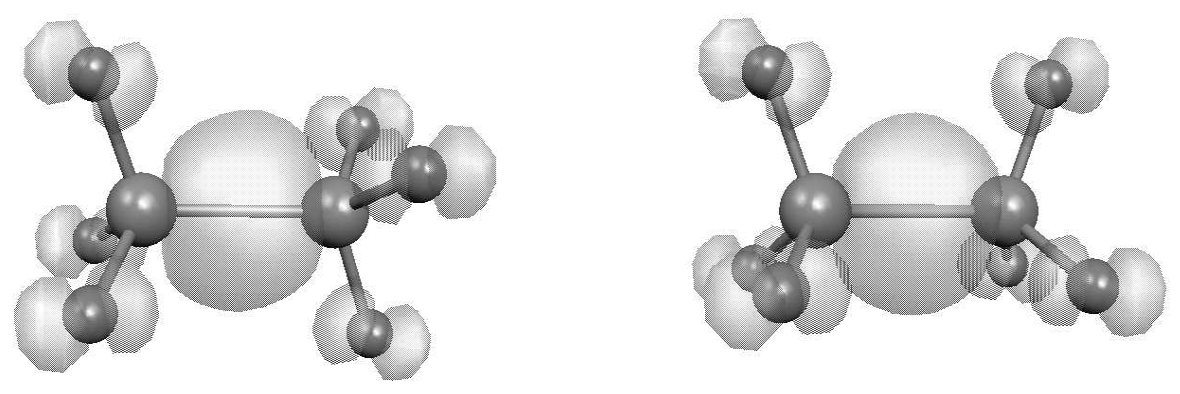

Fig. 6. HOMO for $\mathrm{Si}_{2} \mathrm{H}_{6}$. Left panel: staggered configuration. Right panel: eclipsed configuration

around the Si-Si bond, but with an asymmetry in the direction of the sylil groups. Instead, in the eclipsed conformation, the charge is again delocalized on the Si-Si bond with antibond character, but with some preferential charge on the sylil side when viewed in a plane with four hydrogen atoms. In addition, the delocalization volume is larger in the staggered conformation.

Finally, we consider the $\mathrm{Si}_{2} \mathrm{Cl}_{6}$ molecule $\left(\mathrm{Si}_{2} \mathrm{Br}_{6}\right.$ behaves similarly), which in its staggered configuration has the charge localized on the Si atoms, with a very clear $\sigma$-character, but with some asymmetry in the sylil group directions. This is similar to the eclipsed configuration, where the charge distributes in much the same way, except in that it is completely symmetric around the Si-Si bond. The above results suggest that the low, but significant, barriers that hinder internal rotation may induce different specific nucleophilic attack mechanisms.

\section{Concluding Remarks}

We have performed DFT calculations on $\mathrm{Si}_{2} \mathrm{H}_{6}, \mathrm{Si}_{2} \mathrm{~F}_{6}, \mathrm{Si}_{2} \mathrm{Cl}_{6}$, and $\mathrm{Si}_{2} \mathrm{Br}_{6}$ of the evolution of the electronic energies, chemical hardness and chemical potentials as a function of torsion angle. For all these molecules at the DFT-B3LYP/6$311++\mathrm{G}^{* *}$ level, the staggered conformation is predicted to be the most stable one. Moreover, except for $\mathrm{Si}_{2} \mathrm{~F}_{6}$, it is softer than the eclipsed configuration due to a different charge delocalization at the LUMO orbital.

Low, but significant, energy barriers hinder internal rotation. For $\mathrm{Si}_{2} \mathrm{H}_{6}$ the chemical potential and hardness remains quite constant during the torsion process, while the other molecules show different degrees of electronic density rearrangement as a function of the torsion angle. However, it was not possible to characterize precisely the reactivity behavior just on the basis of the 

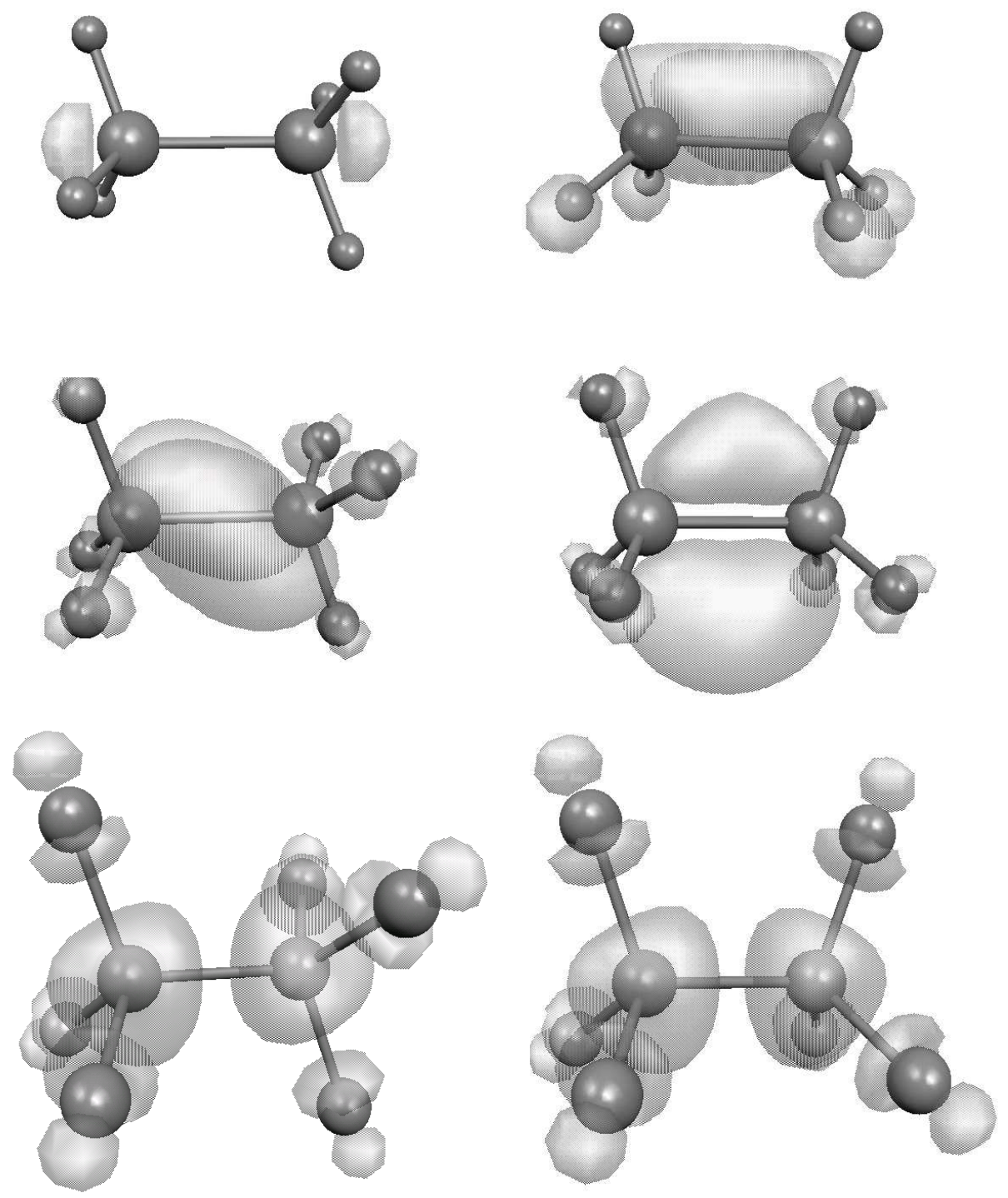

Fig. 7. LUMO for the different molecules considered. Left panel: staggered configuration. Right panel: eclipsed configuration. From top to bottom, $\mathrm{Si}_{2} \mathrm{H}_{6}, \mathrm{Si}_{2} \mathrm{~F}_{6}$ and $\mathrm{Si}_{2} \mathrm{Cl}_{6}$.

chemical potential and hardness profiles.

The qualitative analysis of the frontier orbitals shows that for the $\mathrm{Si}_{2} \mathrm{X}_{6}$ series there is little difference between the HOMO staggered and eclipsed charge distributions. This indicates that the effect of the torsional motion on an electrophilic attack is negligible. In contrast, the low but significant barriers that hinder internal rotation may induce different nucleophilic attack mechanisms. 


\section{References}

[1] V. Pophristic, L. Goodman and C.T. Wu, J. Phys. Chem. A105, 7454 (2001).

[2] S.G. Cho, O. K. Rim and G. Park, J. Comp. Chem. 18, 1523 (1997).

[3] M. Jones, JR., Organic Chemistry, (W. W. Norton and Co., New York, 2000).

[4] J. March, Advanced Organic Chemistry, (John Wiley and Sons, New York, 1992).

[5] G. M. Loudon, Organic Chemistry, (Benjamin/Cummings, Menlo Park, California, 1988).

[6] J. McMurry, Organic Chemistry, (Brooks/Cole, Thomson Learning, New York, 1999).

[7] V. Pophristic and L. Goodman, Nature 411, 565 (2001).

[8] J.K. Badenhoop and F. Weinhold, Int. J. Quant. Chem. 72, 269 (1999).

[9] GAUSSIAN 98: M.J. Frisch et al., Gaussian Inc., Pittsburgh PA, 1999 and references therein.

[10] A.H. Romero, M. Kiwi and R. Ramírez, Phys. Stat. Sol. (b) 230, 391 (2002).

[11] R.G. PARr and W. YAng, Density Functional Theory of Atoms and Molecules, Oxford Science Publications, New York, 1988.

[12] R.M. Dreizler and E.K.V. Gross, Density Functional Theory, Springer, Berlin 1990.

[13] R.G. Parr,R.A. Donnelly, M.Levy and W.E. Palke, J. Chem. Phys., 68, 3801 (1978).

[14] R.G. Parr, and R.G. Pearson, J. Am. Chem. Soc., 105, 7512 (1983).

[15] R.G. Pearson Chemical Hardness: Applications from Molecules to Solids; Wiley-VCH Verlag GMBH: Weinheim, 1997.

[16] Pearson, R.G., J. Chem. Educ., 64, 561 (1987); R.G. Pearson, Acc. Chem. Res., 26, 250 (1993).

[17] R.G. Parr and P.K. Chattaraj, J. Am. Chem. Soc., 113, 1854 (1991); P.K. Chattaraj and G.H. Liu, Chem. Phys. Lett., 237, 171 (1995); P.K. Chattaraj, Proc. Indian Natl. Sci. Acad. Part A, 62, 513 (1996); P.W. Ayers and R.G. Parr, J. Am. Chem. Soc., 122, 2010 (2000).

[18] A. Toro-Labbé, J. Chem. Phys. A, 103, 4398 (1999).

[19] See for example: F. JEnsen, Introduction to Computational Chemistry; John Wiley and Sons, Chichester, 1999. 